\title{
ЭКОНОМИКА РЕГИОНА
}

\section{THE ECONOMY OF THE REGION}

УДК 332.142.2(571.6-77)

DOI dx.doi.org/10.24866/1813-3274/2017-1/58-71

\section{B.K. Заусаев ${ }^{1}$}

Дальневосточный научно-исследовательский институт рынка, г. Хабаровск, Россия

E-mail: zausaev_inst@mail.ru

\section{В.П. Бежина ${ }^{2}$}

Дальневосточный научно-исследовательский институт рынка, г. Хабаровск, Россия

E-mail: bezhinav@gmail.com

\section{Н.А. Кручак ${ }^{5}$}

Дальневосточный научно-исследовательский институт рынка, г. Хабаровск, Россия

E-mail: n_kruchak@mail.ru

\section{ТЕРРИТОРИИ ОПЕРЕЖАЮЩЕГО СОЦИАЛЬНО-ЭКОНОМИЧЕСКОГО РАЗВИТИЯ: РЕАЛИИ И ВОЗМОЖНОСТИ}

Аннотация. Дальний Восток России - богатый природными ресурсами макрорегион, граничащий с быстро развивающимися странами Азиатско-Тихоокеанского региона (АТР). Это может стать объективной предпосылкой для вхождения эконо-

${ }^{1}$ Вадим Константинович Заусаев, доктор экономических наук, профессор, научный руководитель ФАУ «Дальневосточный научно-исследовательский институт рынка», г. Хабаровск, Россия.

2 Бежина Виктория Петровна, ведущий экономист ФАУ «Дальневосточный научно-исследовательский институт рынка», г. Хабаровск, Россия.

${ }^{5}$ Кручак Наталья Андреевна, заместитель директора по науке ФАУ «Дальневосточный научноисследовательский институт рынка», г. Хабаровск, Россия.

Для циитирования: Заусаев, В.К., Бежина, В.П., Кручак, Н.А. Территории опережающего социально-экономического развития: реалии и возможности // Азиатско-Тихоокеанский регион: экономика, политика, право. 2016. № 1. С. 58-71.

(C) Заусаев В.К., Бежина В.П., Кручак Н.А., 2017 
мики России на рынки сопредельных стран, где Дальний Восток будет выполнять функцию контактной зоны. Поэтому макрорегиону в последнее время уделяется повышенное внимание. Введение особых режимов хозяйствования в виде территорий опережающего социально-экономического развития (ТОР) - попытка повысить конкурентоспособность региональной экономики и ускорить интеграционные процессы. Они укладываются в национальный сценарий развития Дальнего Востока, который базируется на инновационных производствах и ориентируется на формирование высокопрофессиональных трудовых ресурсов. Рассмотрены три альтернативных сценария развития экономики Дальнего Востока, выделены их особенности и обозначены последствия для макрорегиона при выборе каждого. Проанализированы территориальные особенности распределения проектов, структура создаваемых рабочих мест и инвестиций в основной капитал по видам экономической деятельности, потенциальные возможности повышения рентабельности продаж продукции, реализуемых в ТОР. Проведенный анализ показал специализацию резидентов ТОР на перерабатывающих производствах. Введённые льготы и преференции, а также административная поддержка позволяют повысить эффективность производства. Однако, учитывая высокую затратность экономики макрорегиона, они не обеспечивают необходимую конкурентоспособность. Требуется комплекс мер стратегического и тактического характера, расширяющий возможности новых производств, которые и предложены в данной статье.

Ключевые слова: территории опережающего социально-экономического развития, «полюса роста», структура производств, сценарии развития, эффективность, оценка льгот и преференций, предложения совершенствования. 


\section{Vadim K. Zausaev ${ }^{1}$}

Far Eastern Research Institute of Market Economy, Khabarovsk, Russia E-mail: zausaev_inst@mail.ru

\section{Victoria P. Bezhina ${ }^{2}$}

Far Eastern Research Institute of Market Economy, Khabarovsk, Russia E-mail: bezhinav@gmail.com

\section{Natalya A. Kruchak ${ }^{3}$}

Far Eastern Research Institute of Market Economy, Khabarovsk, Russia E-mail: n_kruchak@mail.ru

\section{ADVANCED SPESIAL ECONOMIC ZONES: REALITIES AND POTENTIALITIES}

Abstract. The Russian Far East is a macro-region, which is rich in natural resources, bordering with the rapidly developing countries of the Asia-Pacific region (APR). It gives the opportunity for the entering of the Russian economy to the markets of bordering countries. The Far East is to become the contact zone. A rapt attention has been drawn to the macroregion recently. Initiation of Advanced Special Economic Zones (ASEZ) is an attempt to increase the competitiveness of the regional economy and to speed up the integration process. $t$ coincides with the national scenario of the Far East development, which is based on innovative industries. Besides, this scenario focuses on the creation of highly qualified labor resources. Three alternative scenarios of economic development and its specifics of the Far East are considered. In addition, consequences are specified for the macro-region. The territorial features of distribution of projects, the structure of jobs created and investment in fixed capital expenditure on types of economic activities, potential opportunities to enhance profitability of sales of products were analyzed for projects are realized to the ASEZ. Through analysis, it is possible to identify that ASEZ residents is specialized in manufacturing activities. The production efficiency is possible to raise in response to exemptions and preferences as well as administrative support. However, it does not provide the necessary competitiveness because of the high cost of the macro-

${ }^{1}$ Vadim K. Zausaev, Doctor of Economics, Professor of the Far Eastern Research Institute of Market Economy, Khabarovsk, Russia.

${ }^{2}$ Victoria P. Bezhina, Leading Economist of the Far Eastern Research Institute of Market Economy, Khabarovsk, Russia.

${ }^{3}$ Natalya A. Kruchak, Deputy Director of Research, Far Eastern Research Institute of Market Economy, Khabarovsk, Russia.

For citting: Zausaev, Vadim K., Bezhina, Victoria P., Kruchak, Natalya A. Advanced special economic zones: realities and potentialities ASIA-PACIFIC RIM: Economics, Politics, Law. 2017. N 1. P. 58-71. 
region`s economy. A set of strategic and tactical measures are required. It extends the capabilities of new enterprises that proposed in this article.

Key words: Advanced Special Economic Zones, «growth pole», production structure, development scenario, efficiency, evaluation of exemptions and preferences, recommendation for streamlining.

Дальний Восток России - это не только дотационный, но и наиболее удалённый от основных рынков страны макрорегион. Сегодня, в изменившихся реалиях европейских санкций и участия России в вооруженных конфликтах на Ближнем Востоке - как никогда перспективным видится возможность сотрудничества со странами АТР. Последнее переходит в разряд «долгосрочных национальных интересов», отвечая «тенденциям мирового развития» [1].

В настоящее время приоритетным направлением развития региональной политики на Дальнем Востоке является введение особых режимов хозяйствования, к которым относятся территории опережающего социально-экономического развития [2]. Это попытка формирования полюсов роста. Основоположник этой теории Ф. Перру считал, что фундаментальным принципом экономики является неравенство экономических субъектов и наличие доминирующих и подчинённых единиц [3]. Первые являются основой наиболее прогрессивных отраслей, содержат в себе движущую силу экономического развития за счёт выпуска уникальной (либо редкой) на мировом рынке продукции, использования передовых достижений науки, техники и технологий. Эти отрасли - «полюсы роста», которые, в первую очередь, инициируют, а затем распространяют развитие на окружающее пространство. Ими могут выступать отраслевые кластеры.

Сильная сторона подобной модели развития в том, что она получила признание в качестве основной теории зарождения и распространения экономического роста. В её основе лежит эффект доминирования. Мощные, быстрорастущие отрасли обладают эффектом привлечения к себе других отраслей. Вокруг доминирующей единицы изменяются форма и содержание экономических отношений. Доминирующая отрасль и зависящие от нее фирмы создают особую макросреду. Попав в сферу влияния доминирующей структуры, любая другая фирма должна учитывать прямое или косвенное принуждение, исходящее из полюса. Это изменяет общие условия рыночного равновесия, то есть соотношения между затратами, выпуском и ценами в данном пространстве. Параметры «полюсы роста» отклоняются от параметров в других местах общенационального (или общемирового) экономического пространства, становятся частично независимыми. В новом поляризованном пространстве экономические единицы ведут себя уже не как 
конкуренты, а как члены единого, системно организованного целого. Совокупная эффективность действий партнеров повышается. Из стихийной, агрессивной, неорганизованной конкуренции она становится «коллективной», превращается в соревнование. Изменение природы конкуренции влияет на весь механизм распределения ресурсов, то есть на движение капиталов внутри отрасли и между ними. В его основе лежит теперь не только стремление обеспечить максимальную прибыль для каждого предприятия, но и для их совокупности (макроединицы). А это означает, что норма прибыли отдельных предприятий не регулируется величиной их собственного капитала.

Изменение природы конкуренции может существенно сказываться и на ценах. В рамках макроединицы они не являются уже функцией регулирования спроса и предложения, а становятся функцией высшей формы управления, организующей производство и воздействующей на спрос.

Доминирующая макроединица представляет собой «полюс роста». Она порождает «эффект агломерации», объединяя дополняющие друг друга виды деятельности в одно целое. «Полюсы роста», под которыми можно понимать и фирму, и отрасль, и комплекс отраслей, и отраслевой кластер, обладающие сильным «эффектом увлечения», образуют «зоны» и «оси развития» на локальных территориях. Важнейшая задача экономической политики государства заключается в создании таких «полюсов роста» и сознательном управлении распространением их эффекта.

В настоящее время на Дальнем Востоке сформировано 13 TOP в 8 субъектах: «Кангалассы» - Республика Саха (Якутия); «Камчатка» - Камчатский край; «Надеждинская», «Михайловский», «Большой Камень» - Приморский край; «Хабаровск», «Комсомольск» - Хабаровский край; «Приамурская», «Белогорск» Амурская область; «Южная», «Горный воздух»- Сахалинская область; «АмуроХинганская» - Еврейская автономная область; «Беринговский» - Чукотский автономный округ.

Магаданская область - единственный субъект в макрорегионе, который не имеет ТОР, так как на его территории функционирует особая экономическая зона. Но здесь прорабатывается проект создания ТОР с горно-металлургической специализацией.

Правительством Российской Федерации неоднократно предпринимались попытки формирования точек роста, способных стимулировать развитие Дальнего Востока. Начиная с 90-х гг. XX в., на территории региона создавались свободные и особые экономические зоны. Сравнительный анализ показывает, что ТОР имеют существенно большие привилегии: налог на прибыль 0-5\% на 5 лет и не менее 10\% на следующие 5 лет; налог на имущество организации 0-2,2\%; налог на землю 0\% на срок, определенный нормативно-правовыми актами субъектов; налог на добычу полезных ископаемых 0-0,8\% на 10 лет; страховые взносы 7,6\% на 10 лет; уско- 
ренная процедура возмещения налога на добавленную стоимость - 10 дней. Кроме того, вводятся административные льготы: предоставление инвесторам земельных участков в аренду без проведения торгов с момента получения ими статуса резидента; отсутствие у резидентов обязательств по получению разрешений на привлечение и использование иностранных работников в пределах квот, величина которых определяется наблюдательным советом; строительство объектов инфраструктуры и их дальнейшее функционирование осуществляется Управляющей компанией; инвесторы, взявшие кредит на строительство объектов инфраструктуры, получают субсидии на возмещение процентной ставки по кредитам, в размере до $100 \%$ от ставки рефинансирования; сокращение времени проведения контрольных проверок и получение разрешительной документации, внеплановые проверки проводятся только по согласованию с Министерством Российской Федерации по развитию Дальнего Востока. Функционирует режим свободной таможенной зоны. Всё это направлено на повышение инвестиционной привлекательности субъекта и конкурентоспособности экономики макрорегиона.

На 1 января 2017 г. Корпорацией развития Дальнего Востока в качестве резидентов ТОР зарегистрировано 111 бизнес-проектов. Распределение их по субъектам макрорегиона представлено на рис. 1. Лидируют Приморский (26 проектов) и Хабаровский (20 проектов) края.

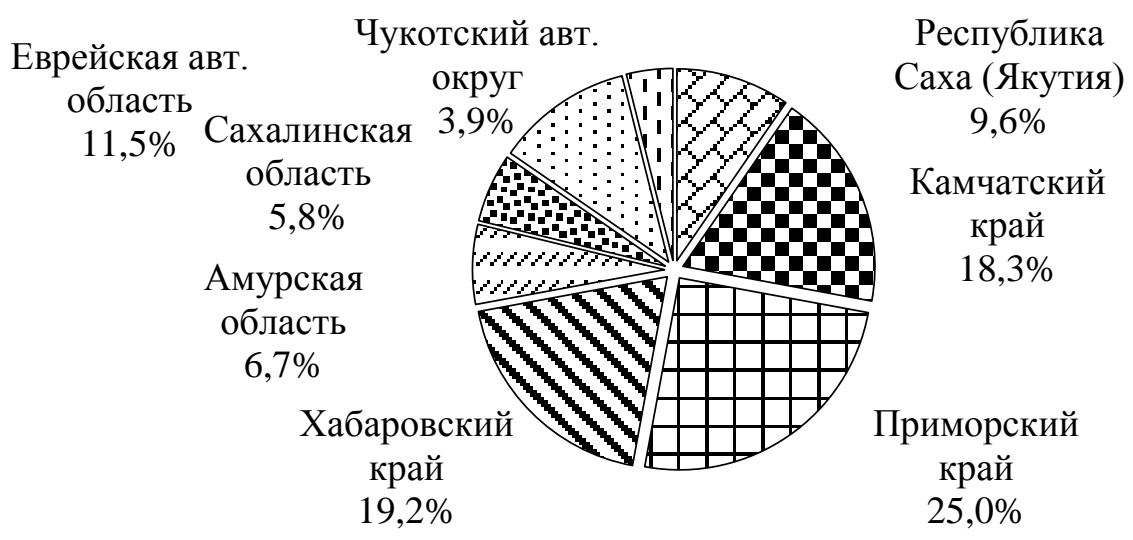

Puc. 1. Распределение проектов, принятых к анализу, по территории Дальнего Востока, \%

Структура занятых по видам экономической деятельности (ВЭД) представлена на рис. 2. На обрабатывающие производства приходится $63,5 \%$, сельское хозяйство - $14,2 \%$, транспорт и связь - 12,4\%. Всего на Дальнем Востоке за счёт резидентов ТОР планируется создать 23,3 тыс. рабочих мест. 


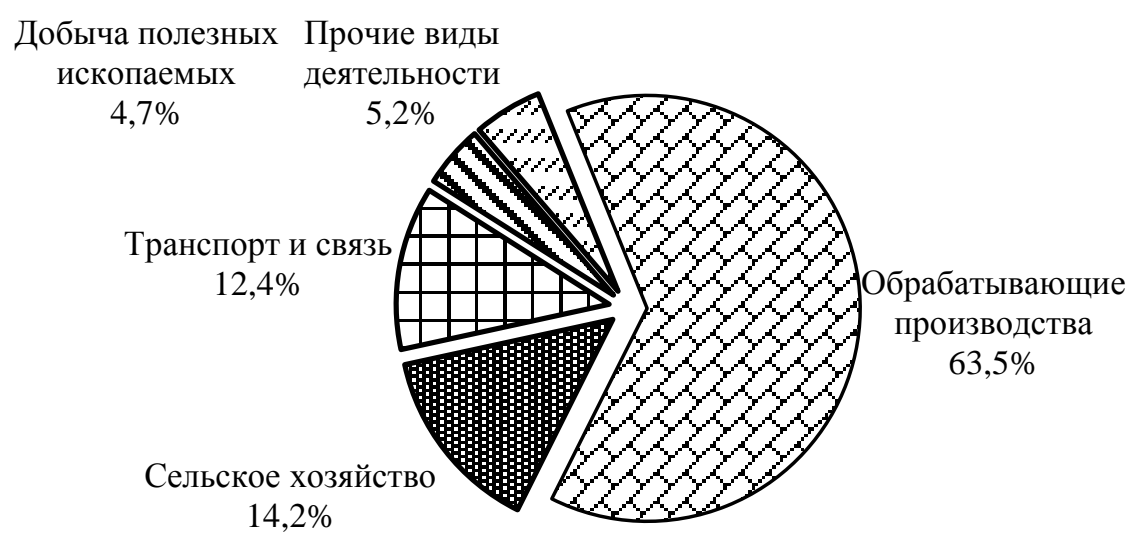

Puc. 2. Структура создаваемых рабочих мест по видам экономической деятельности в субъектах Дальнего Востока, \%

Объем инвестиций в основной капитал по проектам резидентов ТОР к 2020 г. составит 641,7 млрд руб., из которых 73,4\% будут вложены в обрабатывающие производства (сельское хозяйство - 14,8, транспорт и связь - 6,0, прочие виды деятельности - 5,8\%). Явно просматривается преимущество обрабатывающих производств. Это говорит о стремлении предпринимателей строить предприятия с повышенной добавленной стоимостью.

Вместе с тем, проведённые укрупнённые расчёты основных макропоказателей эффективности (производительность труда, инвестиционная отдача, сальдированный финансовый результат) по ВЭД, заявленные резидентами, показали наихудшие значения в обрабатывающих производствах. В большинстве случаев они ниже среднерегиональных показателей. Следовательно, ускорение экономическому развитию субъекта эти производства не придадут.

По субъектам РФ в ДВФО менее благоприятные потенциальные возможности улучшить динамику основных макропоказателей за счёт резидентов ТОР наблюдаются в Хабаровском крае. В целом же по регионам Дальнего Востока наибольшую прибавку к ВРП дадут ТОР Амурской области (16,2\%), наименьшую - ТОР Республики Саха (Якутия) - 0,08\%.

Интересен анализ влияния налоговых льгот на рост рентабельности продаж продукции резидентов ТОР. Расчёт делался по предоставленным бизнес-планам для 2020 г. (рис. 3). Наибольший прирост в Чукотском автономном округе $(9,0)$, наименьший - в Хабаровском крае (5,8 п.п.).

Таким образом, введение особых режимов хозяйствования позволяет повысить эффективность бизнеса. Но хватит ли мер государственной поддержки резидентов ТОР для нивелирования объективного удорожания? 


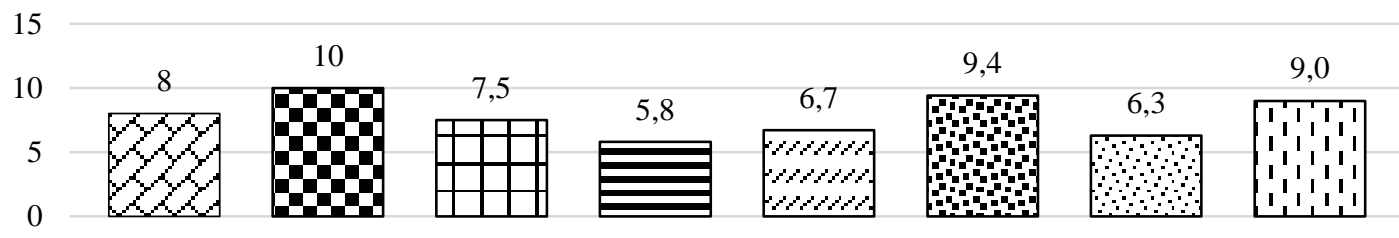

$\square$ Республика Саха (Якутия) ФКамчатский край

曰Хабаровский край

๑ Амурская область

曰Еврейская авт. область

$\square$ Чукотский авт. округ

\section{ППриморский край \\ घСахалинская область}

Puc. 3. Прирост рентабельности продаж резидентов ТОР в сравнении с обычным режимом хозяйствования в субъектах Дальнего Востока, п.п.

Экономика Дальнего Востока объективно высоко затратна. Поэтому в период рыночных преобразований ускоренное развитие получили сырьевые (рентные) отрасли, продукция которых имеет благоприятную конъюнктуру и востребована сопредельными государствами. Высокие издержки производства определяются воздействием четырёх фундаментальных факторов: удалённость от основных рынков страны; окраинность; северность; пионерность освоения. Их нельзя устранить, можно только нивелировать за счёт соответствующих государственных действий.

В условиях плановой экономики себестоимость дальневосточной продукции была выше аналогов, произведённых в других регионах страны, в 1,5-1,7 раза. В настоящее время по некоторым повышающим факторам картина изменилась. Так, по заработной плате разница уменьшилась. Региональный бизнес в целях конкурентоспособности экономит на заработной плате своих работников.

В то же время усилилось удорожающее влияние транспортных и энергетических тарифов. Так, в строительной отрасли удорожание составляет 1,8 , а по отдельным видам продукции - до 2,8 раза. По величине прожиточного минимума превышение в макрорегионе против среднероссийского значения в 2016 г. составляло 1,5 раза.

Проведённые расчёты показали, что экономия по налогу на имущество и социальным платежам резидентов ТОР по субъектам Дальнего Востока колеблется от $1,6 \%$ в Амурской области до $6,1 \%$ в Чукотском автономном округе. Если учесть льготы по налогу на прибыль, то экономия повысится: от 6,8\% в Хабаровском крае до 11,4\% в Республике Саха (Якутия). Но прибыль ещё необходимо получить. Поэтому, в соизмерении с объективным удорожанием производства в ДФО, вводимые льготы не обеспечивают конкурентоспособность региональной продукции. Необходимы более кардинальные действия по совершенствованию механизмов развития ТОР. Но прежде необходимо определиться с перспективным сценарием развития в макрорегионе. 
Исходя из формирующихся в макрорегионе процессов и геостратегических задач, имеющихся знаний и опыта работы в регионе, авторам видятся три сценария развития [4]. Первый - «проб и ошибок». Он формируется в условиях, когда отсутствует системное видение будущего развития макрорегиона и нет ответа на вопрос о роли Дальнего Востока в России. По сути, это консервативно-сырьевой или инерционный вариант развития, обеспечивающий постепенное вхождение экономики Дальнего Востока в АТР. В этой модели сохраняются факторы роста, заложенные в предыдущие годы. Базируются они на достаточно высокой инвестиционной активности в нефтегазовом секторе экономики. Дальнейшее усиление получит сырьевая специализация. Перспективы создания масштабных перерабатывающих производств в ресурсодобывающем секторе ограничатся первичными переделами. Во внешнеэкономической деятельности акцент будет сделан на Китае. Он активизирует свою инвестиционную деятельность. В ограниченных масштабах развитие получат концессионные отношения с привлечением иностранного капитала. Реально ухудшение динамики доходов населения и потребительского спроса, что отрицательно скажется на развитии здравоохранения, образования и жилищнокоммунальной сферы. Ожидается процесс сокращения демографического и кадрового потенциала, особенно в качественном отношении.

Второй сценарий - «бросок в глобализацию» - имеет либерально-сырьевую основу с усилением логистического направления, посредством которого осуществляется массированное вхождение России через Дальний Восток в экономику АТР. Широкое распространение получат концессионные отношения. Они коснутся наиболее масштабных месторождений нефти, газа, железной руды, угля и др. Крупнейшие иностранные корпорации станут главной движущей силой развития региона.

Реализация его базируется на усилении транзитной роли региона, диверсификации внешнеэкономических связей (Китай, Япония, КНДР, Республика Корея и др.). Осуществятся масштабные транспортные проекты «Европа - АТР (Япония)», а также нефтегазовые трубопроводы «Дальний Восток - АТР». Драйвером здесь выступит Сахалин с железнодорожными мостами на материк и о. Хоккайдо (Япония), энергомостом «Сахалин - Япония».

Социальная политика сведётся к минимизации гарантий для местного населения. Усилится экономическая дифференциация населения по доходам и качеству жизни. Отток населения приобретёт массовый характер. Возрастут геостратегические риски, снизится управляемость макрорегиона со стороны российского государства, создадутся предпосылки для экономической потери Дальнего Востока. Вместе с тем, исходя из соотношения «результаты - затраты», этот сценарий развития будет наиболее эффективной.

Третий сценарий - Дальний Восток - драйвер российской экономики в XXI веке. Он базируется на идее высокой потребности в более отдалённой перспективе 
России и сопредельных государств не только в традиционных природных ресурсах, но и в пресной воде, пространстве для размещения возобновимых источников энергии (солнечных, ветровых приливных и др.), экологически чистом животном белке (биологические ресурсы моря). Российский Дальний Восток эту потребность удовлетворить способен. Сделать это, не нанося ущерб безопасности нашей страны, возможно при реализации инновационной (национальной) модели развития макрорегиона. Однако данный сценарий требует значительных вложений в качественную модернизацию экономики, рост человеческого капитала. Реализация долгосрочных проектов в области нефте- и газодобычи, транзитного транспорта, магистральной трубопроводной сети, лесной, угольной и рыбной промышленности должно идти на принципах устойчивого природопользования. Это потребует интенсификации воспроизводства возобновимых природных ресурсов, развития перерабатывающих производств, в том числе на основе иностранных инвестиций и «технологического трансферта», обеспечивающих рост конкурентоспособности продукции на внешних рынках. Концессионные отношения будут преследовать национальные интересы.

Масштабным международным проектом должно стать комплексное освоение природных ресурсов Охотского моря. Имеются в виду не только традиционные биологические и нефтегазовые ресурсы, но и использование энергии приливов, минеральных ресурсов шельфа (железно-марганцевые конкреции) и др.

Развитие производственной и социальной инфраструктуры, образования, здравоохранения, культуры, жилищно-коммунальной сферы обеспечит создание трудового потенциала нового качества. При стягивании его на наиболее благоприятные по условиям проживания территории возрастает роль юга региона как места размещения больших и малых селитебных центров.

Потребуется новая модель внешнеэкономического сотрудничества. Учитывая исторический опыт Японии в освоении южной части Сахалина и вышеназванные проекты, её можно формировать на базе сопряжения островной и японской экономик. Движение в этом направлении уже началось. Это позволит области стать центром интеграции (зоны интенсивных контактов) Российского Дальнего Востока и Японии и рассматривать её как пилотный проект создания в других субъектах макрорегиона подобных зон экономического сотрудничества.

Первый и второй сценарии базируются на реализации естественных преимуществ макрорегиона: рентных сырьевых ресурсах и географическом положении. Они и эксплуатируются достаточно интенсивно в настоящее время. Третий - предполагает развитие перерабатывающих переделов, то есть производства продукции с более высокой добавленной стоимостью, расширенное воспроизводство возобновимых природных ресурсов.

Исходя из нашего опыта изучения Дальнего Востока и его геостратегической значимости для будущего России, акцент следует сделать на третьей модели. Но 
так как эффект от неё наступит только в долгосрочном периоде, то важным становится реализация таких проектов, как ТОР. Он, с одной стороны, нацелен на важные стратегические задачи, с другой - является тактически популярной мерой, позволяющей привлечь внимание и получить эффект действий уже сейчас.

Для того, чтобы «точки роста» заработали в полную силу, необходима дополнительная система мер по совершенствованию механизма ТОР. Начинать его следует с решения общерегиональных проблем. Выше рассмотренные фундаментальные факторы высокой затратности экономики Дальнего Востока усугубляют общероссийские проблемы: отсутствие «длинных» кредитов, неразвитость производственной и социальной инфраструктуры, дефицит квалифицированной рабочей силы. Учитывая также дефицитность федеральных и региональных бюджетов и, следовательно, ограниченность государственной поддержки, необходимы чётко выверенные приоритеты в развитии ТОР.

Прежде всего, надо вспомнить опыт освоения южного Сахалина Японией в 1905-1945 гг. [5, с. 13-16]. Во-первых, он был самодостаточным: вывозилось промышленной продукции больше в 2 раза, чем ввозилось. Во-вторых, экономика развивалась вокруг сырьевых отраслей: лесной, угольной, рыбной. С одной стороны, создавались предприятия по воспроизводству возобновимых природных ресурсов, с другой - развивались высокие перерабатывающие переделы (целлюлознобумажные заводы). В-третьих, государство поддерживало инфраструктурные проекты: построена железная дорога, аэропорты и др. В-четвёртых, в целях самообеспечения развивались сельское хозяйство и углехимия.

Подобный опыт диктует ставить в центр цепочек добавленной стоимости сырьевые производства, содержащие ренту. Первый шаг в этом направлении сделан через «льготы в обмен на инфраструктуру». Распространив же налоговые льготы через кумулятивную систему, можно заинтересовать ресурсодобывающие предприятия в развитии высоких переделов. Смысл кумулятивной системы - предоставление минимальных льгот собственно ресурсодобывающим предприятиям. Например, резиденту, разрабатывающему проект в ресурсопользовании, установить пониженную ставку налога на прибыль, а также по НДПИ. Если он начинает воспроизводить потребляемый им ресурс и ведёт геологоразведку недр, то ему предоставляется льгота по арендной плате. Когда приобретает перерабатывающее оборудование и строит ДОК или ГОК, то на этот передел обнуляются также налоги на прибыль, на имущество, земельный.

При дальнейшем развитии транспортной, энергетической инфраструктуры, при соблюдении принципов экологической безопасности предоставляется льгота по таможенным пошлинам на ввозимые для настоящих целей оборудование и материалы, а также освобождается от уплаты налога на добавленную стоимость. Следующий шаг - подготовка кадров для своего предприятия в ТОР - развитие профессио- 
нального образования и науки, системы медицинского обслуживания. В этом случае устанавливается пониженная ставка страховых взносов, например, в 20\%. Государство ничего не теряет, так как проект является новым производством и выпадение доходов бюджета не происходит. Подобный механизм можно реализовать также в проектах ГЧП, РИП и др.

Необходимо учесть негативный опыт создания особых экономических зон на Дальнем Востоке. Один из последних - Портовая особая экономическая зона в г. Советская Гавань. Особые режимы хозяйствования, создающие благоприятные возможности для прихода бизнеса, - необходимые, но не достаточные действия. Требуется большая конкретика в виде прорывных проектов и мер их государственной поддержки. Причём эти проекты должны максимально вписываться в естественную среду регионального воспроизводства, а не конкурировать и, тем более, не замещать исторически сложившиеся и действующие отрасли и производства. Они должны выполнять геостратегическую роль, то есть решать долговременные фундаментальные задачи. Из современных ТОР им отвечают в полной мере «Комсомольск» и «Большой Камень». Они - потенциальные полюсы роста. Первый инновационного перерабатывающего кластера, второй - океанического машиностроения.

В рамках промышленной политики России необходимо развернуть масштабную противозатратную деятельность, особенно в естественных монополиях и крупных госкорпорациях. Здесь есть существенные резервы снижения себестоимости: опережающий рост производительности труда над заработной платой, редукция заработной платы топ-менеджеров, освобождение от непрофильных активов и др.

В условиях дефицитности федерального и региональных бюджетов и низкого уровня инфраструктурного обустройства территории Дальнего Востока необходимо активнее использовать механизмы государственно-частного партнерства. Такой опыт нарабатывается. Необходимо его распространить в ТОР.

Серьёзную критику вызывают бизнес-планы проектов. Они выполнены на невысоком уровне. Вряд ли под них можно получить кредиты банков. Вызывает сомнения заявленная высокая эффективность проектов. Некоторые показатели в 10 раз и более превышают среднеотраслевые оценки. Корпорации развития Дальнего Востока следует активнее привлекать региональных экспертов. В свою очередь, и региональные органы власти должны участвовать в этом процессе, соотнося направления деятельности потенциальных резидентов, их эффективность со стратегическими приоритетами и целевыми установками своего региона.

Наконец, необходимо распространить особый режим хозяйствования не только на новые, но и действующие предприятия. Дефицит «длинных денег» и высокий процент - долговременная проблема. Действующему бизнесу её решить проще, используя прибыль или, в качестве залога, имеющийся капитал. Но, чтобы не снизить 
налогооблагаемую базу регионального и местного бюджетов, следует ввести «планку отсечения», приняв за основу налоговые и социальные платежи на уровне 2-3 последних лет.

При развитии механизма ТОР будут возникать проблемы правового и экономического характера. Предлагается начать решать их на примере пилотного ТОР «Комсомольск». Это уникальный по структуре экономики и ценностным ориентирам населения центр промышленной агломерации «Комсомольск - Амурск - Солнечный». Не случайно здесь действует Долгосрочный комплексный план социально-экономического развития. Реализация ТОР «Комсомольск» должна показать, по какой модели развития двигаться Дальнему Востоку, возможно ли в макрорегионе создавать инновационные промышленные комплексы. Или развиваться следует на сырьевых отраслях, в лучшем случае, с первичными переделами.

В рамках этого проекта следует расширить территорию ТОР не только на весь г. Комсомольск-на-Амуре, но и сопредельные с ним Амурский, Комсомольский и Солнечный районы. Тогда цепочки добавленной стоимости смогут формироваться не только в машиностроении, но и в других отраслях промышленности (лесной, нефтеперерабатывающей, цветной, рыбной).

В целях реализации одной из основных задач - закрепление населения и повышение качества жизни - предлагается установить здесь выплату дальневосточных и стажевых надбавок из федерального бюджета. Учитывая, что дополнительные выплаты коснутся только работающих в реальном секторе экономики, с учётом потерь социальных платежей, они составят порядка 40 млрд руб. Это - большая нагрузка на бюджет, и задачу надо решать поэтапно. Но будет и компенсация в виде выхода из тени части бизнеса, роста НДФЛ, активизации малого и среднего предпринимательства.

Что касается тактических действий, то необходимо: на региональном уровне разработать концепцию каждого ТОР; утвердить для резидентов форматы бизнеспланов, идентичные требованиям ведущих банков страны; увеличить срок предоставления налоговых льгот по федеральным налогам для резидентов ТОР, реализующих крупные инвестиционные проекты; обеспечить адресное сопровождение крупных резидентов, особенно якорных зарубежных инвесторов; внести изменения в Налоговый Кодекс Российской Федерации по установлению налоговых льгот индивидуальным предпринимателям-резидентам ТОР; упростить порядок получения кредитов под проекты резидентов от профильных институтов развития; изыскать возможность финансирования проектно-сметной документации на строительство инфраструктурных объектов в ТОР за счет средств Фонда развития Дальнего Востока и Байкальского региона. 


\section{СПИСОК ЛИТЕРАТУРЫ}

1. Послание Президента Федеральному Собранию от 01.12.2016 г. [Электронный ресурс] // Администрация Президента России : офиц. сайт. - Режим доступа: http://kremlin.ru/events/president/news/53379.

2. О территориях опережающего социально-экономического развития в Российской Федерации [Электронный ресурс] : федеральный закон от 29.11.2014 г. № 473-Ф3. - Режим доступа: http://www.consultant.ru/document/cons _doc_LAW_172962/.

3. Перру, Ф. Экономика XX века // Мировая экономическая мысль. Сквозь призму веков. Т. 4. - М. : Мысль, 2004. - С. 402-413.

4. Заусаев, В. К. Сценарии развития и конкурентоспособность экономики российского Дальнего Востока / В. К. Заусаев, Г. И. Бурдакова, Н. А. Кручак // ЭКО. 2016. - № 1. - С. 26-35.

5. Хорошавин, А. В. Сахалин в 21 веке: новый вектор развития / А. В. Хорошавин, В. К. Заусаев. - Хабаровск : Хабаровская краевая типография, 2012. - 430 с.

\section{REFERENCES}

1. The President's Address to the Federal Assembly on 2016.12.01. President's website. Available at: http://kremlin.ru/events/president/news/53379 (accessed 03 February 2017). (In Russian).

2. On Priority Socioeconomic Development Areas in the Russian Federation. The Federal Law on November 29, 2014 No. 473-FZ. Available at: http://www.consultant.ru/document/cons_doc_LAW_172962/ (accessed 03 February 2017).

3. Perroux F. Ekonomika XX veka [Economy of the twentieth century]. Mirovaya ekonomicheskaya mysl'. Skvoz' prizmu vekov [World economic thought. Through the prism of centuries]. Moscow: Mysl' Publ., 2004, Vol. 4, p. 402-413.

4. Zausaev V.K., Burdakova G.I., Kruchak N.A. Stsenarii razvitiya i konkurentosposobnost' ekonomiki rossiiskogo Dal'nego Vostoka [Development Scenarios and Economic Competitiveness of the Far East of Russia]. ECO, 2016, no. 1, p. 26-35.

5. Khoroshavin A.V., Zausaev V.K. Sakhalin v 21 veke: novyi vektor razvitiya [Sakhalin in XXI century: a new growth vector]. Khabarovsk: Khabarovsk Regional Printing House, 2012. 430 p. 